\title{
EXPLOSIVE GROWTH OF SHEAR-HEATING INSTABILITIES IN THE DOWN-SLOPE CREEP OF ICE SHEETS
}

\author{
By DAVID A. YUEN, * \\ (Department of Geological Sciences and C.I.R.E.S., University of Colorado, Boulder, \\ Colorado 80309, U.S.A.) \\ MARC R. SAARI, \\ (Department of Geology, Arizona State University, Tempe, Arizona 85287, U.S.A.) \\ and Gerald SCHuberT \\ (Department of Earth and Space Sciences, University of California, Los Angeles, California 90024, U.S.A.)
}

\begin{abstract}
The time-scale for the onset of the explosive growth of a finite-amplitude shear-heating instability in the down-slope creep of a thick ice sheet is determined by integrating the equation for the temporal evolution of the temperature-depth profile subsequent to a sudden change in ice thickness. All instabilities eventually grow explosively after a prolonged period of simmering or relatively slow monotonic growth. Though times for explosive growth depend on initial and final ice thicknesses, surface temperature, accumulation rate, basal heat flux, and ice rheological parameters, the explosion times are extremely sensitive to the activation energy and the pre-exponential constant of the ice-creep law. Sudden increases in ice-sheet thickness of $1-2 \mathrm{~km}$ due to a rapid climatic deterioration can lead to explosive instability and melting of the basal shear layer in only thousands of years if ice-creep activation energies are lower than about $60 \mathrm{~kJ} \mathrm{~mol}^{-1}$.
\end{abstract}

RÉSUMÉ. Croissance explosive d'instabilités de cisaillement thermique dans le fluage le long des pentes des grandes masses de glace. L'échelle de temps pour l'établissement d'une croissance explosive d'instabilités de cisaillement thermique d'amplitude finie pour la déformation le long des pentes d'une grande masse de glace est déterminée en intégrant l'équation d'évolution temporelle du profil vertical de température, à la suite d'un changement brusque de l'épaisseur de glace. Toutes les instabilités croissent explosivement après une période prolongée près du point critique ou après une croissance relativement lente et monotone. Les temps nécessaires à une croissance explosive dépendent des épaisseurs initiales et finales, de la température de surface, du taux d'accumulation, du flux géothermique et des paramètres rhéologiques de la glace; les

\section{PHYSICAL PARAMETER VALUES AND NOTATION}

$\begin{aligned} A & =8.75 \times 10^{-13} \mathrm{~Pa}^{-3} \mathrm{~s}^{-1} & & \text { Flow-law constant } \\ E & =60 \mathrm{~kJ} \mathrm{~mol}^{-1} & & \text { Activation energy } \\ R & =8.314 \mathrm{~J} \mathrm{~mol}^{-1} \mathrm{~K}^{-1} & & \text { Gas constant } \\ \rho & =900 \mathrm{~kg} \mathrm{~m}^{-3} & & \text { Density } \\ k & =2.51 \mathrm{~W} \mathrm{~m}^{-1} \mathrm{~K}^{-1} & & \text { Thermal conductivity }\end{aligned}$

*Present address: Supercomputer Institute and Department of Geology and Geophysics, University of Minnesota, Minneapolis, Minnesota 55455, U.S.A. temps d'explosion étant extrêmement sensibles à l'énergie d'activation et au facteur multiplicateur de la loi exponentielle de fluage de la glace. De brusques accroissements de l'épaisseur de 1 à $2 \mathrm{~km}$. Causés par une rapide détérioration climatique peuvent engendrer une instabilité explosive et une fonte de la couche basale de cisaillement en seulement un millier d'années si les énergies d'activation du fluage de la glace sont inférieures à environ $60 \mathrm{~kJ} \mathrm{~mol}^{-1}$.

ZuSAMMENFASSUNG. Explosive Ausbreitung von Instabilitäten im Abwärtskriechen von Eisdecken infolge der Scherwärme. Der zeitliche Ablauf der explosiven Ausbreitung einer Instabilităt im Abwärtskriechen einer dicken Eisdecke mit begrenzter Amplitude, ausgelöst durch Scherwärme, wird durch Integration der Gleichung für die zeitliche Entwicklung des Temperatur-Tiefe-Profils im Gefolge einer plötzlichen Änderung der Eisdicke gewonnen. Alle Instabilitäten breiten sich gegebenenfalls nach einer längeren Periode des Gärens oder des relativ langsamen, monotonen Anwachsens explosiv aus. Wenn auch Zeitpunkte für explosive Ausbreitung von der anfänglichen und endgültigen Eisdicke, von der Oberflächentemperatur, der Akkumulationsrate, dem Wärmefluss am Untergrund und rheologischen Parametern der Eises abhängen, so sind die Explosionszeiten ausserordentlich empfindlich gegen die Aktivationsenergie und die Multiplikationskonstante des EisKriechgesetzes. Plötzliche Anstiege der Eisdicke von $1-2 \mathrm{~km}$ infolge einer raschen Klimaverschlechterung können zu explosiver Instabilităt und zum Schmelzen der Scherschicht am Untergrund in nur wenigen tausend Jahren führen, wenn die Aktivationsenergien des Eiskriechens niedriger als etwa $60 \mathrm{~kJ} \mathrm{~mol}^{-1}$ sind.

\begin{tabular}{|c|c|c|}
\hline$k$ & $=1.33 \times 10^{-6} \mathrm{~m}^{2} \mathrm{~s}^{-1}$ & Thermal diffusivity \\
\hline$q_{\mathrm{b}}$ & $=41.8 \mathrm{~mW} \mathrm{~m}^{-2}$ & Basal geothermal flux \\
\hline$g$ & $=9.8 \mathrm{~m} \mathrm{~s}^{-2}$ & Gravity constant \\
\hline$\alpha$ & $=0.1^{\circ}$ & Basal slope \\
\hline$T_{\mathrm{s}}$ & $=223 \mathrm{~K}$ & Surface temperature \\
\hline$v_{0}$ & $=0.1 \mathrm{~m} \mathrm{year}^{-1}$ & Accumulation rate \\
\hline$U_{0}$ & & Horizontal surface velocity \\
\hline$T_{\mathrm{b}}$ & & Basal temperature \\
\hline
\end{tabular}


Critical height

$h_{0}$

Initial ice-sheet thickness

$h_{\mathrm{g}}$

Height necessary for fast instabilities

$\Delta h$

Perturbation of ice-sheet thickness

$t_{\mathrm{gr}}$

Inverse growth rate

$t_{\mathrm{m}}$

Basal melting time

\section{INTRODUCTION}

The down-slope sliding of large ice sheets is an intrinsically thermo-mechanical problem, since the shear deformation of ice is strongly controlled by its temperaturedependent rheology. Accordingly, viscous dissipation can play an important role in modifying the movement of ice sheets. Clarke and others (1977) and Yuen and Schubert (1979) drew attention to the fact that shear heating could cause instability in ice flows; Schubert and Yuen (1982) suggested that the East Antarctic ice sheet could be vulnerable to this type of creep instability. All of these previous efforts have been based upon arguments drawn from linear stability analyses.

The time-scale for the growth of shear-heating instability in creeping ice sheets is of particular significance in determining the potential physical relevance of the instability. In order for shear-heating instability to exert an influence on the climate system, the instability should grow and significantly affect the dynamics of the ice sheet in a time comparable to or less than the time-scale of the basic glacial cycle $O\left(10^{5}\right.$ year $)$. Shear-heating instability in ice is a type of explosive instability that also occurs in combustion phenomena. The instability occurs suddenly or explosively after a prolonged period of simmering or slow monotonic growth. Thus the time-scale associated with the non-linear evolution of an explosive-type instability generally exceeds the growth time predicted by linear theory (Buckmaster and Ludford, 1983, chapter 3). A non-linear calculation is therefore required to determine quantitatively the simmering time before the onset of explosive instability in creeping ice sheets. The determination of these times is the primary purpose and contribution of this paper.

We begin in section 2 with a description of the onedimensional model (Schubert and Yuen, 1982) of an ice sheet creeping down-slope and give the equations governing the evolution of shear-heating instability. The manner in which the instability is triggered is discussed next and we conclude the section by describing the numerical methods used to monitor the non-linear growth of an instability. Section 3 presents the numerical results and discusses how the onset time for explosive instability depends on the environmental and rheological parameters of the model. It turns out that the time to get explosive instability depends very sensitively on the rheological parameters of ice. Instability time-scales can differ by orders of magnitude for variations in the rheological parameters encompassed by uncertainties in our knowledge of the creep properties of polycrystalline ice. We close in section 4 with a summary and a discussion of the implications of our results for the occurrence of shear-heating instability in real ice sheets.

\section{GOVERNING EQUATIONS AND NUMERICAL METHODS}

We will employ a simple one-dimensional model (Clarke and others, 1977; Schubert and Yuen, 1982) to investigate finite-amplitude shear-heating instabilities. Admittedly, these models do not include factors such as the horizontal advection of cold ice and the reduction of the shear stress upon a local increase in temperature. Both of these are stabilizing influences. Nonetheless, our studies should yield valuable insight into the physical mechanisms at work, since the set of two-dimensional, thermo-mechanical boundary-layer equations may contain some serious numerical difficulties (Morland, 1984). In the future it should be feasible with supercomputers, like the CRAY-2, to solve with fine meshes the complete two-dimensional set of thermo-mechanical equations. This would obviate the need for approximating solving the boundary-layer equations with their attendant problems of specifying the correct up-stream conditions.

We will consider the motion of a horizontally infinite ice sheet with thickness $h$ inclined at an angle $\alpha$ with respect to the horizontal. The coordinate system is oriented with the $y$-axis perpendicular to the slope. The ice surface is at $y=h$ and the base is located at $y=0$. The distribution of shear stress $\tau$ in this model is

$$
\tau=\rho g(h-y) \sin \alpha
$$

where $\rho$ is the density of ice and $g$ is the gravitational acceleration. The approximate one-dimensional equation governing the temporal evolution of the temperature $T$ is

$$
\frac{\partial T}{\partial t}=k \frac{\partial^{2} T}{\partial y^{2}}-v(y) \frac{\partial T}{\partial y}+\frac{2 A}{k}\{\rho g(h-y) \sin \alpha\} \exp \left(-\frac{E^{*}}{R T}\right)
$$

where $t$ is the time, $k$ is the thermal conductivity, $\mathrm{k}$ is the thermal diffusivity, $E^{*}$ is the activation energy for the creep of ice, $A$ is the pre-exponential constant in the ice rheological law, $R$ is the universal gas constant, and $v$ is the ice velocity in the direction perpendicular to the slope. We take $v(y)$ to be a linear function of $y, v(y)=v_{0} y / h$; positive $v_{0}$ signifies accumulation. We will consider only accumulation since this condition stabilizes the ice sheet (Clarke and others, 1977). Equation (2) gives the change of temperature with time as the net result of conduction, advection, and viscous dissipation. It is solved subject to the boundary conditions

$$
\begin{array}{ll}
T=T_{\mathrm{s}}, & \text { on } y=h, \\
-k \frac{\partial T}{\partial y}=q_{\mathrm{b}}, & \text { on } y=0
\end{array}
$$

where $q_{\mathrm{b}}$ is the geothermal heat flux entering the bottom of the ice sheet.

The down-slope flow velocity is determined from the creep law of ice, where we have taken the Glen's power law with the power-law index $n=3$ and the Arrhenius rate factor (Paterson, 1981, chapter 3).

$$
\frac{\partial u}{\partial y}=2 A[\rho g(y-h) \sin \alpha]^{3} \exp \left(\frac{-E^{*}}{R T}\right) .
$$

This equation is integrated subject to the condition

$$
u=0 \quad \text { on } y=0 .
$$

The third-order system in Equations (2)-(6) represents a standard two-point boundary-value problem that can be solved by straightforward numerical techniques (Yuen and Schubert, 1979). Solutions to the steady-state version of Equations (2)-(6) have been obtained by Yuen and Schubert (1979) and Schubert and Yuen (1982).

The physical constants used in most of the calculations are listed at the beginning of this paper. The rheological parameters $E^{*}$ and $A$ are taken from Clarke and others (1977) and Paterson (1981, chapter 3). We have also varied $A$ and $E^{*}$ in our calculations, as the pre-exponential parameter may be uncertain by creep data at ice shelves. We have varied these parameters in order to understand the physical effects from uncertainties in these parameters. For 

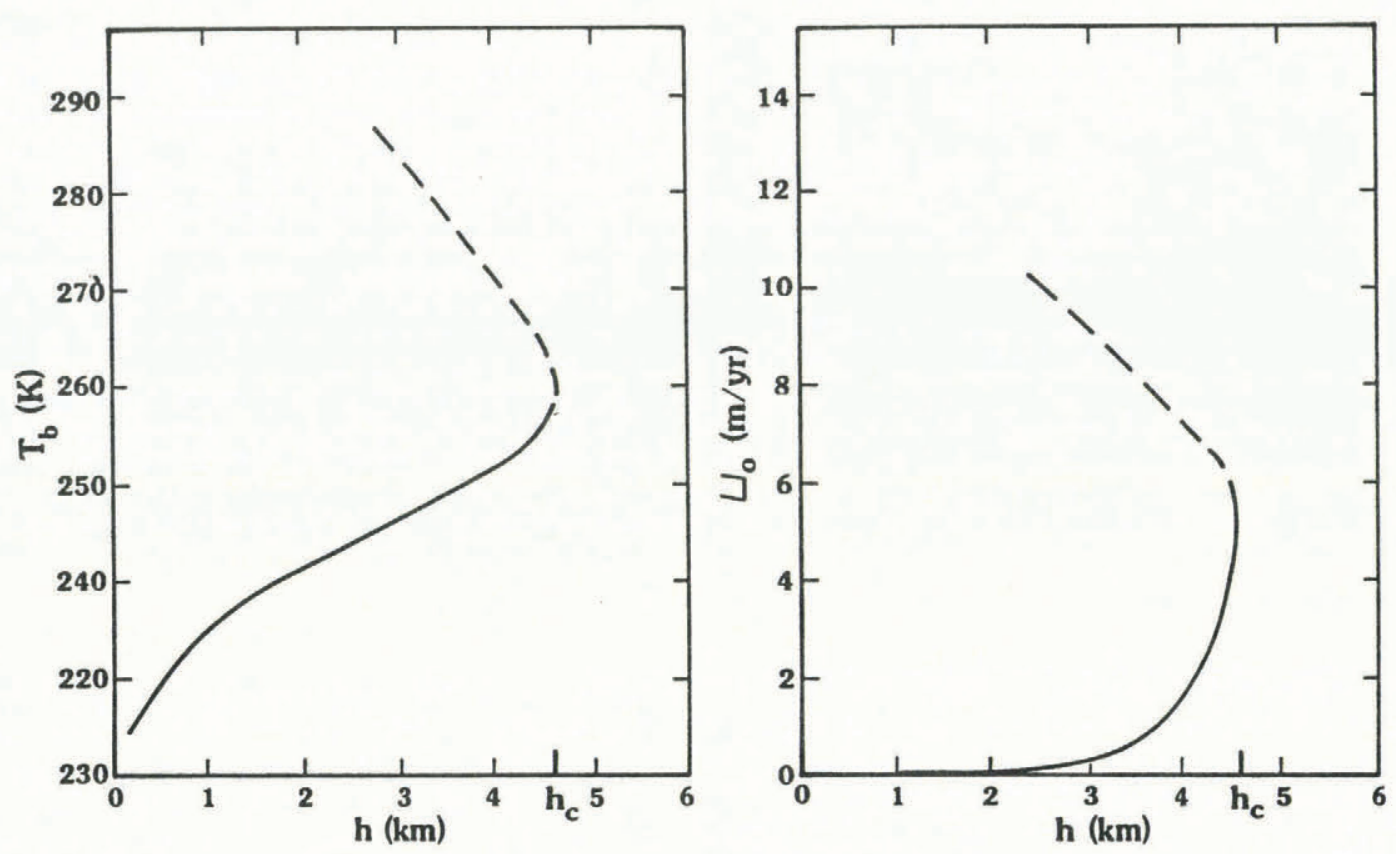

Fig. 1. Multiple steady states in the down-slope creep of a constant-thickness ice sheet. Basal temperature and surface velocity are plotted as functions of ice thickness. The critical height is denoted by $h_{c} ;$ for $h>h_{c}$ there are no steady-state solutions. Rheological and physical parameters are taken from the text.

example, below $-10^{\circ} \mathrm{C}, E^{*}$ could vary between 42 and $84 \mathrm{~kJ} \mathrm{~mol}^{-1}$ (Paterson, 1981, chapter 3).

Due to the exponential dependence of the viscosity upon the temperature, the non-linear system in Equations (2)-(6) yields multiple steady-state solutions (Clarke and others, 1977; Yuen and Schubert, 1979). Figure 1 shows an example of the multiple steady states. For a given equilibrium ice thickness there exist two states with different basal temperatures and down-slope surface velocities. The solid parts of the curves delineate the sub-critical solutions while the dashed parts of the curves (drawn schematically) indicate the super-critical solutions. The super-critical branch cannot be reached by a forward integration of the complete time-dependent Equations (2)-(6). It can only be obtained by treating the steady equations as a non-linear two-point boundary-value problem. On the other hand, the sub-critical branch can be arrived at by treating the equations either as a parabolic system with the time dependence present in Equation (2) or as an elliptic system with the time-derivative in Equation (2) omitted. We have found that the nature of the multiple steady-state solutions does not come from the power-law dependence of the rheology. Rather, it is the temperature-dependent rheology by itself which is responsible for these shear-heating instabilities.

We observe in Figure 1 that there is a maximum height $h_{\mathrm{c}}$ above which no steady-state solutions can exist. Super-critical solutions (dashed curves) have bottom temperatures greater than the melting temperature of ice. At this stage, the model is no longer valid. Hence, it is only the sub-critical branch which is of interest here. Schubert and Yuen (1982) have called attention to the closeness of these critical heights to the present-day ice thickness in East Antarctica. They argued that a finite-amplitude creep instability might be possible through a sudden increase of the ice thickness above $h_{\mathrm{c}}$. However, the growth times of these instabilities were not evaluated. Our task in this paper is to conduct a thorough numerical investigation of the growth times of these instabilities. They will be seen to have explosive character similar to instabilities encountered in combustion (e.g. Kassoy and Poland, 1980). However, the explosion can be preceded by a long period of simmering or slow monotonic growth.

We consider a basic steady sub-critical state with thickness $h_{0}$ and at $t=0$ suddenly change the ice-sheet thickness by $\Delta h$. The total ice thickness $h$ in Equation (2) is then $h_{0}+\Delta h$. Other ice-thickening histories can be investigated but the sudden increase represents a limiting case that is expected to yield the most sensitive ice-sheet response. Our model does not allow the ice sheet to thin in response to the imposed abrupt increase in thickness. Because thinning would tend to quench the shear-heating instability (Fowler and Larson, 1980), our results provide only a lower bound on the time to explosive instability. Nevertheless, our calculations are important because they delineate the conditions under which explosive instability could conceivably occur on a fast enough time-scale to be a potentially significant climatic factor. Incorporation of the ice-thinning effect is necessary, however, for a complete and final assessment of the potential physical importance of shearheating instability. For marching the temperature equation in time, an initial temperature profile must be supplied. The initial thermal profile is divided into two parts. The temperature of the newly added ice of thickness $\Delta h$ is taken to be isothermal at the surface temperature $T_{0}$. Below this layer the initial temperature follows the thermal distribution given by the steady-state solution with an equilibrium height of $h_{0}$. The accumulation rate is held constant except for the sudden thickening that occurs at $t=0$. Thus, $v=$ $v_{0} y / h$ for the initial state computation of $T$ with $h=h_{0}$ and $v$ is given by $-v_{0} y /\left(h_{0}+\Delta h\right)$ in the computation of $T$ for $t>0$.

We have employed a partial differential equation solver developed by Sewell (1982). The program approximates spatial derivative operators using Hermite cubic splines and marches in time using the method of lines. The coefficients of the basis functions are integrated as an initial value system using a stiff differential equation integrator. The accuracy of the program has been tested by calculating the linear growth rates of the thermal disturbances and comparing them with the results of Clarke and others (1977). Typically, 30 to 40 unevenly distributed nodal points are adequate for accurate solutions. Nodal points must be concentrated in the basal shear layer to resolve the large spatial gradients therein. At least ten points have been placed in the shear layers of the cases reported here. The time-discretization error is maintained below $10^{-3}$ based on a relative-error criterion. 


\section{NUMERICAL RESULTS}

3.1 Time for the onset of explosive instability

Figure 2 shows typical time histories of the basal temperature $T_{\mathrm{b}}$ for three activation energies $(50,60$, and $\left.70 \mathrm{~kJ} \mathrm{~mol}^{-1}\right)$ and three values of $\Delta h(1,3$, and $8 \mathrm{~km})$. Other

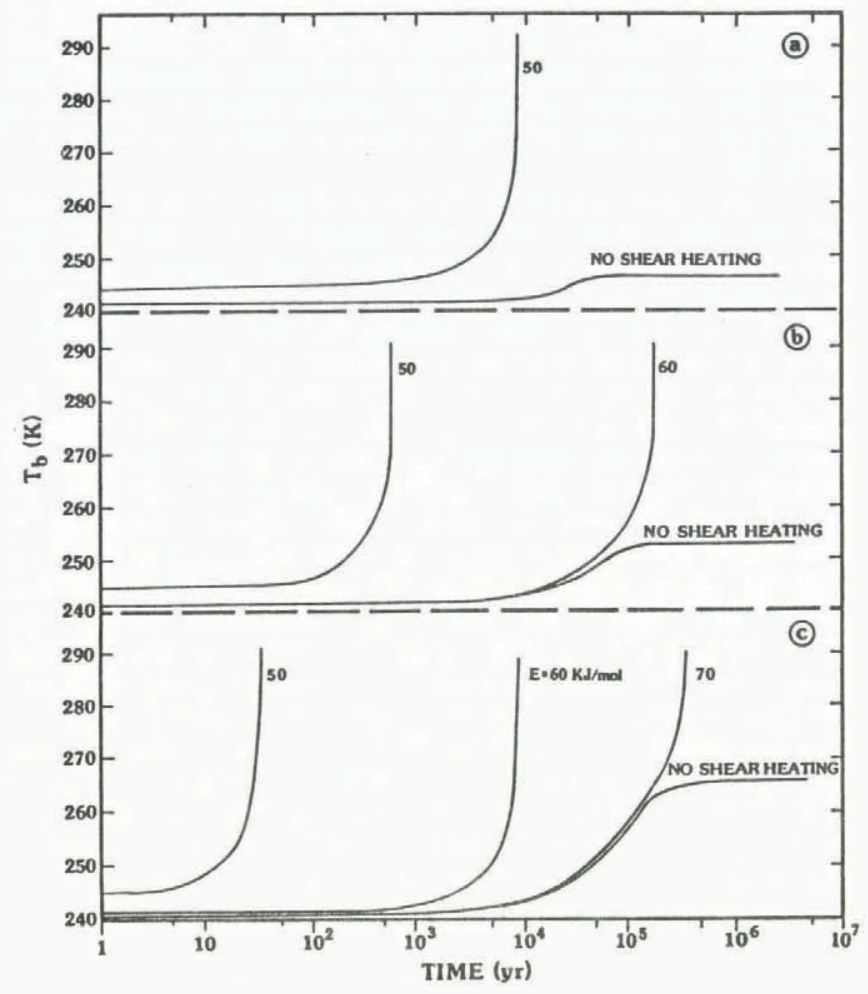

Fig. 2. Temporal evolution of the basal temperature $T_{b}$ following $a$ sudden increase in ice thickness. (a) $E^{*}=50 \mathrm{~kJ} \mathrm{~mol}^{-1}$, initial height $h_{0}=2 \mathrm{~km}$, critical height $h_{c}=2.15 \mathrm{~km}, \Delta h=1 \mathrm{~km} ;$ (b) $E^{*}=50$ and $60 \mathrm{~kJ} \mathrm{~mol}^{-1}$, $h^{c}$ for $60 \mathrm{~kJ} \mathrm{~mol}^{-1}=4.6 \mathrm{~km}, h_{0}=2 \mathrm{~km}, \Delta h=3 \mathrm{~km}$; (c) $E^{\mathrm{c}}=50,60$, and $70 \mathrm{~kJ} \mathrm{~mol}^{-1}, h_{c}$ for $70 \mathrm{~kJ} \mathrm{~mol}^{-1}=9.1 \mathrm{~km}$, $h_{0}=2 \mathrm{~km}, \Delta h=8 \mathrm{~km}$. Other parameters are from the text.

parameter values are given at the beginning of this paper and in all cases $h_{0}=2 \mathrm{~km}$. For shear-heating instability to occur, $h_{0}+\Delta h$ must exceed $h_{\mathrm{c}}$. Because $h_{\mathrm{c}}$ increases with $E^{*}$ for the cases considered in Figure 2, $\Delta h$ must be increased with $E^{*}$ to trigger instability. With $h_{0}=2 \mathrm{~km}$ and $\Delta h=1 \mathrm{~km}$, instability would not occur for $E^{*}=60$ and $70 \mathrm{~kJ} \mathrm{~mol}^{-1}$. Similarly, with $h_{0}=2 \mathrm{~km}$ and $\Delta h=3 \mathrm{~km}$, instability would not occur for $E^{*}=70 \mathrm{~kJ} \mathrm{~mol}^{-1}$. Though this is the main rationale for choosing different values of $\Delta h$ in Figure 2, the calculations nevertheless present us with the opportunity of studying how the growth of the instability depends on $\Delta h$. It should be noted here that these values for $\Delta h$ are used here for the purpose of illustrating the amount required for obtaining an instability. One should, in no way, consider that large values of $\Delta h$, say $3 \mathrm{~km}$, are at all possible. These values of $\Delta h$ are meaningful when viewed in the light of finite-amplitude perturbation analysis.

Initial basal temperature depends on $E^{*}$ and it can be seen particularly clearly in Figure $2 \mathrm{c}$ that $T_{\mathrm{b}}$ initial is higher the lower the activation energy. Figure 2 also shows that for a given $\Delta h$ the time for the onset of explosive instability is shorter for smaller $E^{*}$. A difference in $E^{*}$ of just $10 \mathrm{~kJ} \mathrm{~mol}^{-1}$ can mean a change of two orders of magnitude in the explosion-triggering time (Fig. $2 \mathrm{~b}$ and c). For $\Delta=1 \mathrm{~km}$, only the state with $E^{*}=50 \mathrm{~kJ} \mathrm{~mol}^{-1}$ can become unstable; the explosion occurs after about 8000 years. For a larger increase in ice thickness, $\Delta h=3 \mathrm{~km}$, the $E^{*}=50 \mathrm{~kJ} \mathrm{~mol}^{-1}$ state explodes in only 600 years. For this $\Delta h$, instability also occurs for $E^{*}=60 \mathrm{~kJ} \mathrm{~mol}^{-1}$ but the simmering time is nearly $2 \times 10^{5}$ years. With $\Delta h$ as large as $8 \mathrm{~km}$, explosions occur in only about 30 years for $E^{*}=$ $50 \mathrm{~kJ} \mathrm{~mol}^{-1}$ and 8000 years for $E^{*}=60 \mathrm{~kJ} \mathrm{~mol}^{-1}$. Instability also occurs for $E^{*}=70 \mathrm{~kJ} \mathrm{~mol}^{-1}$ when $\Delta h$ is $8 \mathrm{~km}$ but the time-scale for explosive growth is very long, about 350000 years. We note that this dependence on $E^{*}$ merely reflects the fact that three orders of viscosity change occur in the range of $E^{*}$ between 50 and $70 \mathrm{~kJ} \mathrm{~mol}^{-1}$ for the temperatures under consideration.

We have also plotted in Figure 2 the temperature change in the thickened ice layer arising just from the combined effects of conduction and downward advection of heat due to accumulation. The initial profile is taken from a basic state with an accumulation rate of $-v_{0}$ and a thickness of $h_{0}$. It thus has a thermal boundary layer with a thickness of $O\left(k / v_{0}\right)$ at the bottom (e.g. Clarke and others, 1977). As can be seen, the basal temperature reaches an equilibrium value after a time-scale between $0\left(10^{4}\right.$ year $)$ and $0\left(10^{5}\right.$ year $)$. Even for an $8 \mathrm{~km}$ increment, the final basal temperature does not exceed the melting temperature of ice on account of the cooling effect from advection of cool material downward.

A quantity of interest is the instantaneous growth time of the basal temperature, a time-dependent quantity. It is given by

$$
t_{\mathrm{gr}}(t)=\left[\frac{1}{T_{\mathrm{b}}(t)} \frac{\partial T_{\mathrm{b}}(t)}{\partial t}\right]^{-1}
$$

From a mathematical standpoint, $t_{\mathrm{gr}}$ is to be regarded as a time-dependent inverse growth rate, which in a non-linear problem varies as a function of time. The present definition of $t_{\mathrm{gr}}$ can also be interpreted as the inverse growth rate of the total thermal energy of the system.

A plot of $t_{\mathrm{gr}}$ versus time indicates the different regimes for the growth of the instability. Figure 3 shows such a plot for $E^{*}=45$ and $60 \mathrm{~kJ} \mathrm{~mol}^{-1}$. The physical and rheological parameters are taken from the beginning of this paper. The perturbation $\Delta h$ is $1.0 \mathrm{~km}$. The original heights

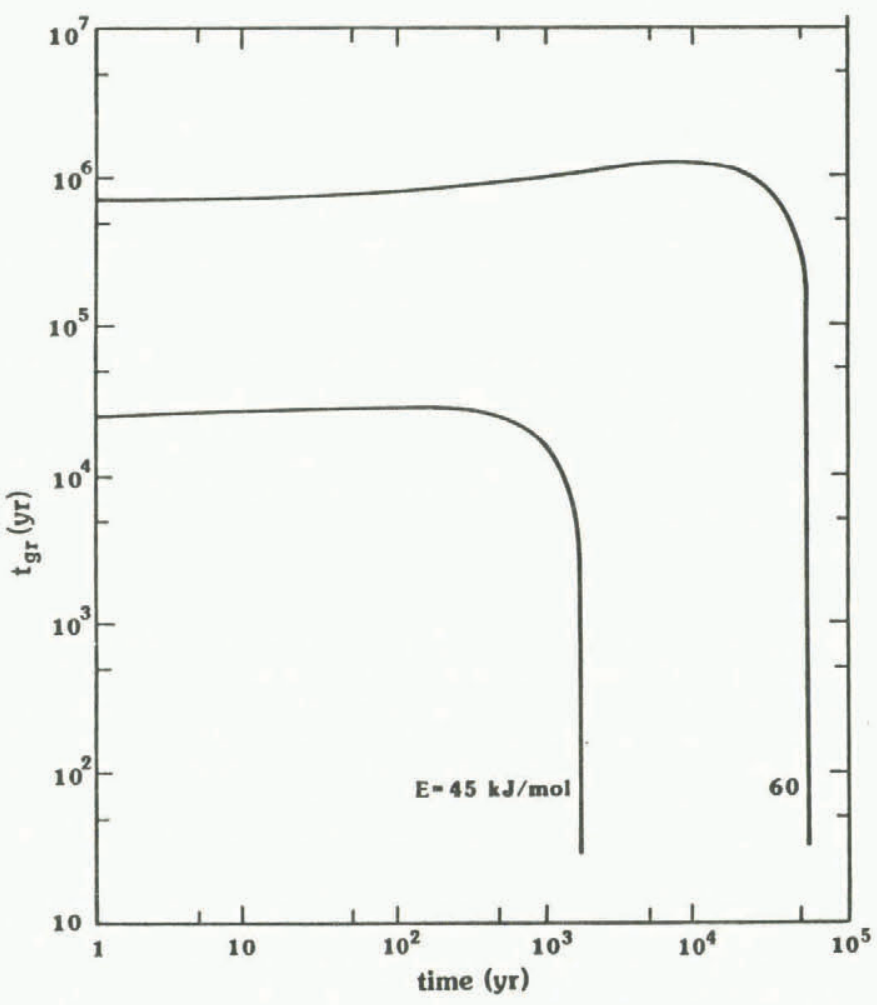

Fig. 3. Inverse growth time $t_{g r}$ of the basal temperature as a function of time. The initial height is $0.95 \mathrm{~h}_{\mathrm{c}}$. For $E^{*}=45 \mathrm{~kJ} \mathrm{~mol}^{-1}, h_{c}=1.4 \mathrm{~km}$, and for $E^{*}=60 \mathrm{~kJ} \mathrm{~mol}^{-1}$, $h_{c}=4.6 \mathrm{~km}$. The perturbation $\Delta h$ is $1 \mathrm{~km}$. Other parameters are the same as in Figure 2. 
are $0.95 h_{\mathrm{f}}$ where the critical heights for $E^{*}=45$ and $60 \mathrm{~kJ} \mathrm{~mol}^{-\mathrm{f}}$ are 1.4 and $4.6 \mathrm{~km}$, respectively. We find that growth time is initially more or less constant in accordance with linear theory (Clarke and others, 1977). After an induction period during which non-linearity begins to exert its influence, $t_{\mathrm{gr}}$ shortens rather precipitously as in the case of combustion phenomena (e.g. Kassoy and Poland, 1980). The rate of growth rises super-exponentially in an unbounded fashion. The ratio of the induction or simmering times between $E^{*}=45$ and $60 \mathrm{~kJ} \mathrm{~mol}^{-1}$ is $0\left(10^{-2}\right)$, demonstrating once again the sensitivity of the growth rates to relatively small variations of the activation energy.

\subsection{Variation of stability characteristics with accumulation} rate

An aspect of the multiple steady states that has not been touched upon previously concerns the effects of accumulation rate. Schubert and Yuen (1982) studied multiple steady states for small values of $\left|v_{0}\right|$, less than $0.3 \mathrm{~m} \mathrm{a}^{-1}$. For greater accumulation rates, the critical ice thickness reaches a maximum (see solid curves in Figure 4) and decreases thereafter with further increases in the rate of downward advection. Figure 4 represents a new class of multiple steady-state solutions charcterized by the distinctive

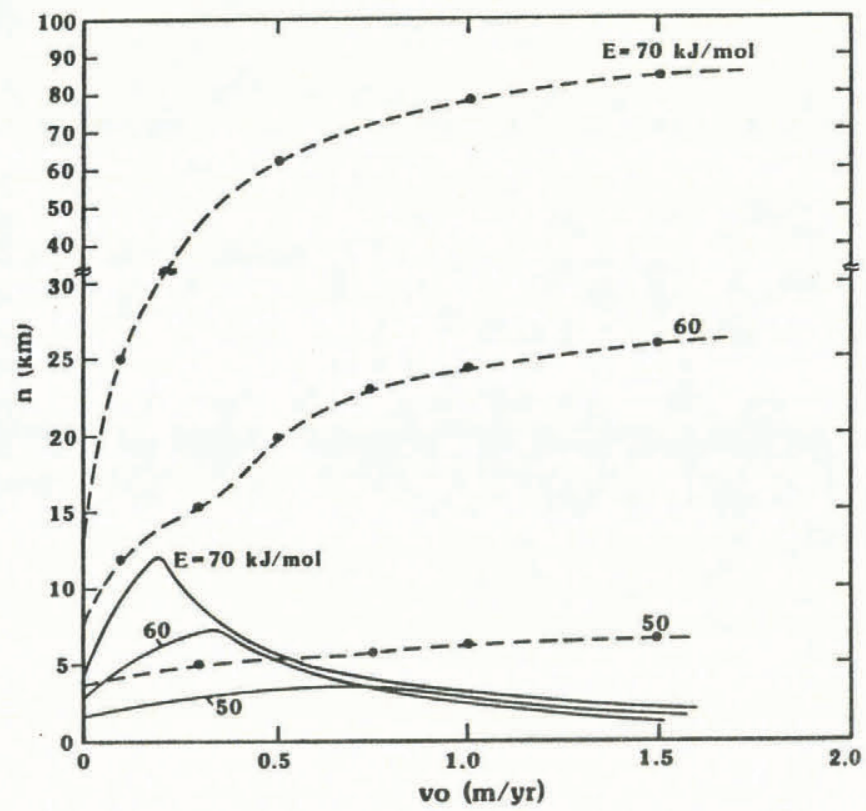

Fig. 4. The critical height $h_{c}$ (solid curves) and the total height (dashed curves) needed to produce fast instabilities as a function of accumulation rate. The criterion for fast instabilities is that $t_{g r}(t=1000$ year $)=10^{3}$ year. The initial thickness is $0.95 h_{c}$. Other parameters are the same as in Figure 3.

property of having two different accumulation rates for a given ice thickness (the results for $h_{\mathrm{c}}$ depicted in Figure 4 can be analytically continued to values of $h$ less than $h_{\mathrm{c}}$ ). The existence of the branch with the larger accumulation rate can be understood in terms of the occurrence of a thin basal thermal boundary layer which serves to facilitate deformation by reducing the shear stress necessary to drive the flow.

Figure 4 also shows the total height $h_{0}+\Delta h$ (dashed curves) needed to produce a growth time of 1000 years after a time of 1000 years has elapsed following the initial perturbation $\left(h_{0}=0.95 h_{\mathrm{c}}\right)$. The magnitude of $\Delta h$ needed to trigger such a rapid instability generally increases with $\left|v_{0}\right|$; it also increases dramatically with $E^{*}$. When $\left|v_{0}\right|$ exceeds $0.5 \mathrm{~m} \mathrm{a}^{-1}$, the necessary $\Delta h$ at $E^{*}=70 \mathrm{~kJ} \mathrm{~mol}^{-1}$ is more than 30 times larger than $\Delta h$ required for $E^{*}=50 \mathrm{~kJ} \mathrm{~mol}^{-1}$. Icethickness perturbations of only a couple of kilometers are adequate to induce fast instabilities when $E^{*}=50 \mathrm{~kJ} \mathrm{~mol}^{-1}$.
3.3. Time for melting: effects of varying rheological and physical parameters

A more physically meaningful measure of the time-scale for creep instability is the time $t_{\mathrm{m}}$ for the basal temperature to reach the solidus temperature of ice. The rheology we have employed is not uniformly valid up to the melting temperature, since the activation energy above $-10^{\circ} \mathrm{C}$ is about twice its value below $-10^{\circ} \mathrm{C}$ on account of significant amounts of recrystallization and grain growth (Weertman, 1983). However, this is of little consequence, for once the runaway process has ensued there is very little difference between the time it takes to reach $-10^{\circ} \mathrm{C}$ or $0^{\circ} \mathrm{C}$ (Fig. 2).

The time to melt is shown in Figure 5 as a function of $\Delta h$ for various activation energies. The rest of the physical and rheological parameters are taken from the beginning of this paper. Figure 5 also includes a curve associated with no shear heating in the energy equation. Solid curves with shear heating correspond to states with an initial height $h_{0}$ of $2 \mathrm{~km}$, while the dashed curves are associated with a smaller $h_{0}$ of $1.4 \mathrm{~km}$. In all cases, viscous heating serves to decrease $t_{\mathrm{m}}$ relative to the case of no frictional heating. Basal melting requires a minimum of about $2 \times 10^{5}$ year to occur when viscous dissipation is not taken into account. However, with frictional heating, $t_{\mathrm{m}}$ can be much less than $2 \times 10^{5}$ year. For $t_{\mathrm{m}}$ to be less than $10^{4}$ year, $\Delta h$ must be at least $30 \mathrm{~km}$ for $E^{*}=70 \mathrm{~kJ} \mathrm{~mol}^{-1}$, at least $8 \mathrm{~km}$ for $E^{*}=60 \mathrm{~kJ} \mathrm{~mol}^{-1}$, but only $2 \mathrm{~km}$ for $E^{*}=50 \mathrm{~kJ} \mathrm{~mol}^{-1}$. By comparing the solid and dashed curves for $E^{*}=50 \mathrm{~kJ} \mathrm{~mol}^{-1}$ and noting that the critical height $h_{\mathrm{c}}$ for $E^{*}=50 \mathrm{~kJ} \mathrm{~mol}^{-1}$ is $2.2 \mathrm{~km}$, we can conclude that the instability is faster the closer the initial thickness is to the critical thickness. Ice-thickness perturbations of $1-2 \mathrm{~km}$ are capable of producing melting within $10^{4}$ year for $E^{*}$ less than about $50 \mathrm{~kJ} \mathrm{~mol}^{-1}$.

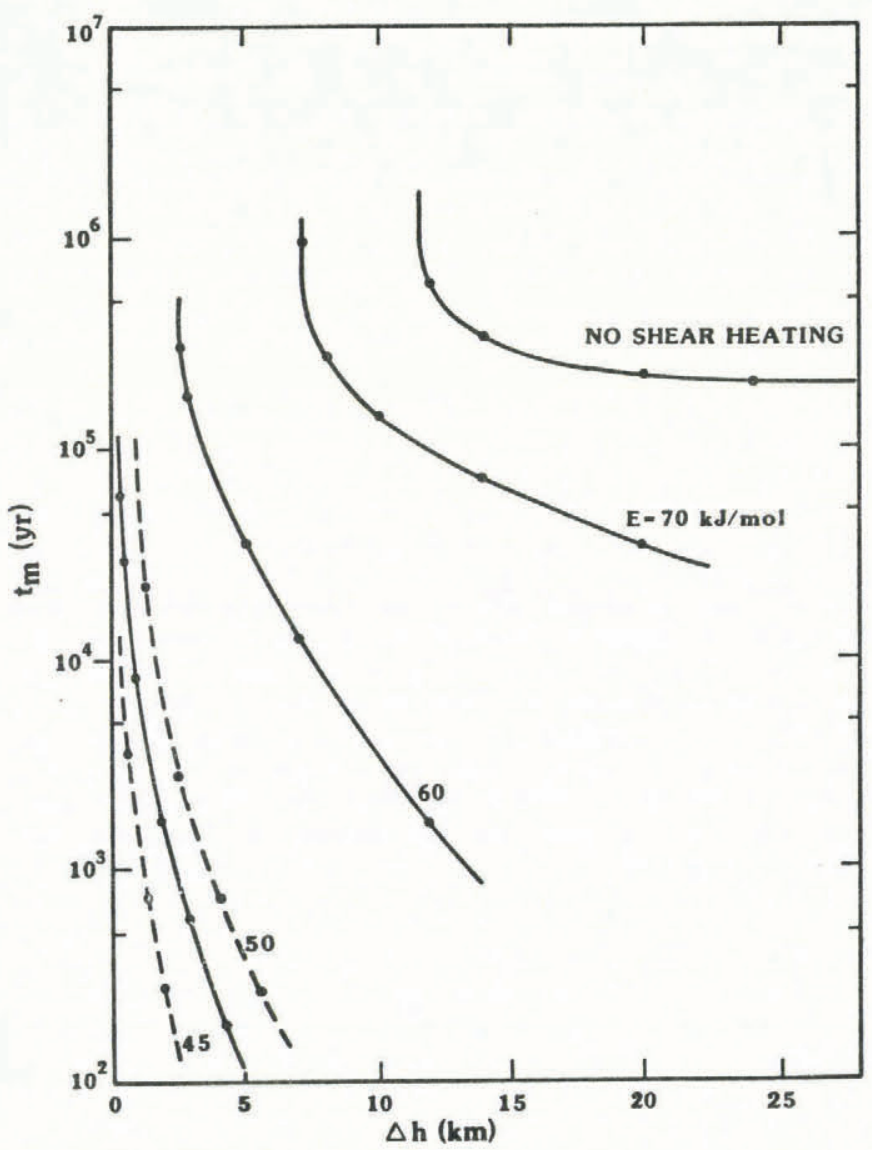

Fig. 5. Time for basal melting as a function of the perturbation ice thickness. Solid curves are for $h_{0}=2 \mathrm{~km}$, while dashed curves represent $h_{0}=1.4 \mathrm{~km}$. No shear heating means that Equation (2) is solved without the frictional heating term present. Other parameters are the same as in Figure 4. 


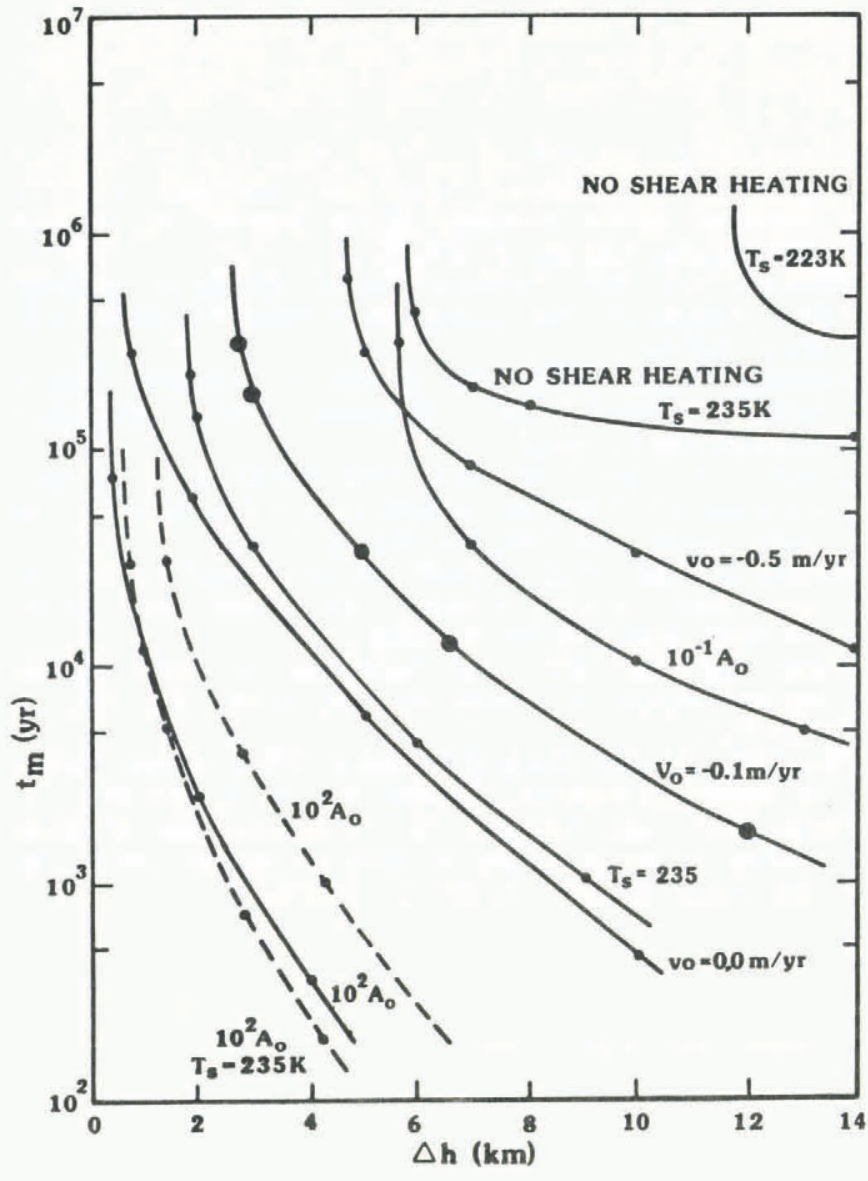

Fig. 6. Melting time as a function of the increase in ice thickness. Solid curves represent initial conditions with $h_{0}=2.0 \mathrm{~km}$, while dashed curves are associated with $h_{0}=1.4 \mathrm{~km}$. An activation energy of $E^{*}=60 \mathrm{~kJ} \mathrm{~mol}^{-1}$ has been employed throughout. Unless otherwise noted in the figure, the other parameters are kept fixed according to the text. The critical heights $h_{c}$ for the cases $\left(10^{2} A_{0}\right.$. $\left.\dot{T}_{S}=223 \mathrm{~K}\right)$ and $\left(10^{2} A_{0}, \dot{T}_{s}=235 \mathrm{~K}\right)$ are respectively 2.4 and $1.8 \mathrm{~km}$.

Effects on $t_{\mathrm{m}}$ due to variations in $A, v_{0}$, and $T_{\mathrm{s}}$ are summarized in Figure 6; in all the cases $E^{*}=60 \mathrm{~kJ} \mathrm{~mol}^{-1}$ Decreases in $A$ and increases in $\left|v_{0}\right|$ stabilize the ice sheet by increasing $t_{\mathrm{m}}$. An increase in $A$ by a factor of 100 $\left(A=100 A_{0} ; A_{0}\right.$ is the nominal value of $A$ given at the beginning of this paper) can lead to fast instabilities for reasonable values of $\Delta h$. (Because the critical height $h$ for the case of $10^{2} A_{0}$ and $T_{\mathrm{S}}=235 \mathrm{~K}$ is less than $2 \mathrm{~km}\left(h_{\mathrm{c}}=\right.$ $1.84 \mathrm{~km}$ ), we took $h_{0}$ in this case to be $1.4 \mathrm{~km}$. For all the solid curves in Figure $6, h_{0}=2 \mathrm{~km}$. For the case $T_{\mathrm{s}}=$ $223 \mathrm{~K}$ and $10^{2} A_{0}, h_{\mathrm{c}}$ is about $2.39 \mathrm{~km}$.) A comparison of the two cases with different $T_{\mathrm{s}}$ but with the same large value of $A=10^{2} A_{0}$ shows that an increase in the surface temperature of $12 \mathrm{~K}$ can reduce $t_{\mathrm{m}}$ by a factor of 5 for $\Delta h$ $=2 \mathrm{~km}$. In general, fast instabilities can be optimized by having low values of $E^{*}$, high values of $T_{\mathrm{S}}$, and large values of $A$. When all of these ingredients act in concert, then $t_{\mathrm{m}}$ approaching $10^{3}$ year is quite feasible for $\Delta h$ between 1 and $2 \mathrm{~km}$.

The way surface temperature influences the instability is explored in greater detail in Figure 7 which shows $h_{\mathrm{cr}}$ and the total ice thickness $0.95 h_{\mathrm{c}}+\Delta h$ necessary to yield a growth time of $10^{3}$ year after an elapsed time of $10^{3}$ year, both as functions of $T_{\mathrm{s}}$. Other rheological and physical parameters are taken from the beginning of this paper. Critical ice thickness increases as the environment becomes colder; $h_{\mathrm{c}}$ increases by about a factor of two when $T_{\mathrm{s}}$ decreases from 240 to $210 \mathrm{~K}$. The magnitude of the icethickness perturbation necessary to give $t_{\mathrm{gr}}\left(10^{3}\right.$ year $)=10^{3}$ year also increases with decreases in $T_{\mathrm{s}}$; the $\Delta h$ required to

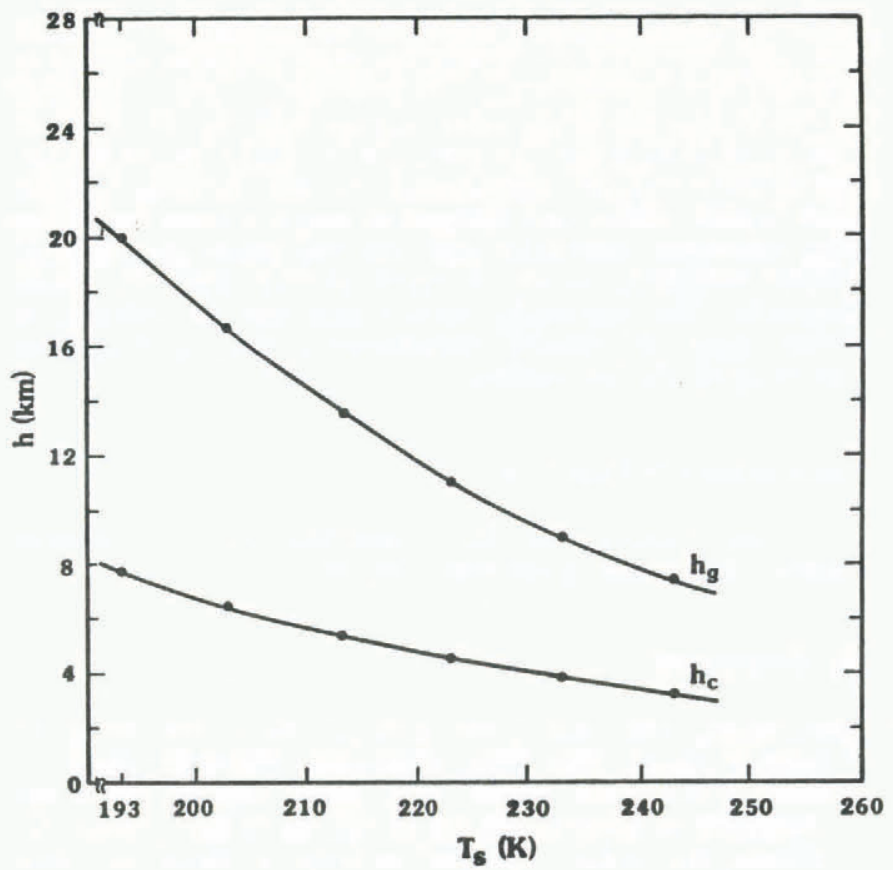

Fig. 7. The critical height and the total height needed for fast instabilities (as defined in the caption to Figure 4) as functions of the surface temperature $T_{s}$. Parameters are taken from the text.

induce instabilities with the same rapid time-scale doubles when $T_{\mathrm{S}}$ is reduced from 240 to $210 \mathrm{~K}$.

\section{SUMMARY AND CONCLUDING REMARKS}

The overall size and internal state of a polar ice sheet have important influences upon our climate system. Of particular significance for the dynamics and stability of an ice sheet is the state of the basal ice (melted or frozen) beneath most of the "grounded" area. Van der Veen and Oerlemans (1984) have shown that the presence of basal melt water can produce a bifurcation in the steady-state solutions for a polar ice sheet. Two different regimes are possible - a fast flow with a high basal temperature and a slow flow with a low basal temperature.

Our work has addressed the feasibility of inducing massive basal melting by explosive shear-heating instability. We have concentrated on obtaining quantitative estimates of the time-scale of this instability and in so doing have imposed finite-amplitude perturbations in the form of thickened ice layers. The particular form of this perturbation was chosen only for its simplicity. Other perhaps more climatically realistic perturbations can also trigger shear-heating instability. For example, we have conducted calculations to show how climatic warming can also lead to massive basal melting by this frictional heating mechanism.

We have demonstrated that creep instabilities can indeed cause melting of the basal ice layer under circumstances for which the ice would not melt without viscous dissipation. More importantly, we have found that the time-scale for melting can be greatly reduced by shear heating even if basal melting would be the long-term fate of a thickened ice sheet without viscous dissipation. Shear-heating instability has been seen to occur in an explosive manner after the thickened ice sheet simmers for what might be a prolonged period of time. Rapid times for the onset of explosion are strongly favored by low activation energies and large values of the pre-exponential factor in the flow law; i.e. fast instabilities are favored by more ductile creep behavior of ice. Short time-scales for melting by shear-heating instability are also induced by low accumulation rates and high surface temperatures.

Our numerical experiments have shown that shearheating instabilities with fast time-scales of $0\left(10^{2}-10^{3}\right.$ year $)$ 
can only be induced in ice sheets by additions of 1-2 km of ice for realistic values of environmental and icerheological parameters. Admittedly, the required perturbations are large, when viewed with the thickness of the present Antarctic ice sheet. While the perturbations are prescribed, without consideration of ice thinning (Fowler and Larson, 1980), our calculations place a lower bound on the time-scale associated with the non-linear evolution of creep instability, which is much shorter than the linear estimates. The time-scales derived here are also relevant to other types of climatic perturbations, such as long-term warming of the ice surface.

\section{ACKNOWLEDGEMENTS}

This research has been supported by U.S. National Science Foundation grant DPP 8215015.

\section{REFERENCES}

Buckmaster, J.D., and Ludford, G.S.S. 1983. The theory of laminar flames. New York, Cambridge University Press.

Clarke, G.K.C., and others. 1977. Strain heating and creep instability in glaciers and ice sheets, by G.K.C. Clarke, U. Nitsan, and W.S.B. Paterson. Reviews of Geophysics and Space Physics, Vol. 15, No. 2, p. 235-47.
Fowler, A.C., and Larson, D.A. 1980. The uniqueness of steady state flows of glaciers and ice sheets. Geophysical Journal of the Royal Astronomical Society, Vol. 63, No. 2, p. 333-45.

Kassoy, D.R., and Poland, J. 1980. The thermal explosion confined by a constant temperature boundary: I - The induction period solution. SIAM Journal on Applied Mathematics, Vol. 39, p. 412-30.

Morland, L.W. 1984. Thermomechanical balances of ice sheet flow. Geophysical and Astrophysical Fluid Dynamics, Vol. 29 , p. $237-66$.

Paterson, W.S.B. 1981. The physics of glaciers. Second edition. Oxford, etc., Pergamon Press. (Pergamon International Library.)

Schubert, G., and Yuen, D.A. 1982. Initiation of ice ages by creep instability and surging of the East Antarctic ice sheet. Nature, Vol. 296, No. 5853, p. 127-30.

Sewell, G. 1982. IMSL software for differential equations in one space variable. Houston, TX, IMSL Inc. (IMSL Technical Report Series No. 8202.)

Veen, C.J. van der, and Oerlemans, J. 1984. Global thermodynamics of a polar ice sheet. Tellus, Vol. 36A, p. 228-35.

Weertman, J. 1983. Creep deformation of ice. Annual Review of Earth and Planetary Sciences, Vol. 11, p. 215-40.

Yuen, D.A., and Schubert, G. 1979. The role of shear heating in the dynamics of large ice masses. Journal of Glaciology, Vol. 24, No. 90, p. 195-212. 